\title{
Joint Effusions And Purpura In Multiply-Transfused Adult Beta-Thalassemia- Clinical Pointers To Diagnosis Of Scurvy
} Prakash A, Pandey AK

\author{
Department of Medicine \\ Lady Hardinge Medical College and Smt. Sucheta \\ Kriplani Hospital, New Delhi \\ India \\ Corresponding Author \\ Anupam Prakash \\ Department of Medicine \\ Lady Hardinge Medical College and Smt. Sucheta \\ Kriplani Hospital, New Delhi \\ India \\ E-mail: prakashanupam@hotmail.com
}

Citation

Prakash A, Pandey AK. Joint Effusions And Purpura In Multiply-Transfused Adult Beta-Thalassemia- Clinical Pointers To Diagnosis Of Scurvy. Kathmandu Univ Med J 2013;44(4):360-362.

\begin{abstract}
Periodic transfusions and effective chelation have ensured that thalassemics survive in to adulthood but their life is punctuated by peculiar problems in adulthood. Three cases of scurvy are being reported presenting uniquely as purpura, right hip joint effusion and right knee joint effusion with haemorrhage in prepatellar and retropatellar bursae, respectively over an 18 month period (2009-2010). The first two cases did give a history of gum bleed. None had any coagulation disturbance or transfusion-transmitted infections or connective tissue disorder. All the three cases responded dramatically to vitamin C supplementation. It is imperative to keep in mind that recurrent blood transfusions are associated with a state of subclinical vitamin C deficiency and overt scurvy may manifest as cumulative number of transfusions increase, as in adult thalassemics.
\end{abstract}

\section{KEYWORDS}

Joint effusion, scurvy, thalassemia, transfusion-dependent, ascorbic acid, vitamin C.

\section{INTRODUCTION}

Lifelong transfusions and effective iron-chelation form the mainstay of therapy for thalassemia major patients and have contributed immensely in improving their quantity and quality of life. Thalassemia patients now grow in to adulthood and this has brought forth a peculiar set of problems. Three adult cases of thalassemia major are discussed, each of whom had a distinct presentation of rare and infrequently-made diagnosis- "scurvy". Scurvy in transfusion-dependent adult thalassemics has not been reported to date.

\section{REPORT OF CASES}

Three adult cases of thalassemia major on regular transfusion and chelation that were noticed to have peculiar features over an 18-month period (2009-2010) are being described; the common clinical features are outlined in table 1 for purposes of brevity. The unique features are being discussed in detail.
Case 1

Patient presented with skin rash on bilateral lower limbs which were non-palpable purpuric spots- multiple and perifollicular (fig 1). History of intermittent gum bleeding was also present for past three to four months. There was no history of fever or diarrhoea in the preceding six weeks, no history of drug ingestion or recurrent trauma at site of skin rash. Clinical features are outlined in table 1 . Rheumatoid factor was positive, although no clinical manifestations of arthritis were present. No similar previous history or family history was present. Dietary history revealed adequate caloric intake but poor intake of fresh fruits and vegetables. Suspecting scurvy, patient was put on oral vitamin C 500 mg daily following which the lesions disappeared in 10-15 days and there has not been any recurrence in the last six months she has been on therapy. 


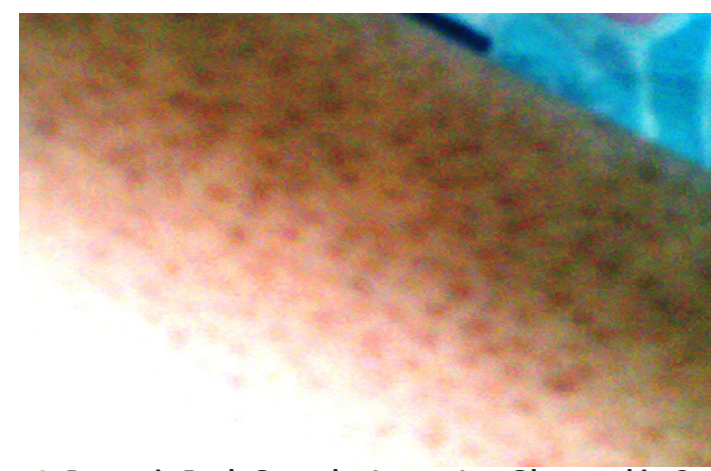

Figure 1. Purpuric Rash Over the Lower Leg Observed in Case 1.

Table 1. Clinical Features of the Three Adult Thalassemia Cases on Regular Transfusion-Chelation.

\begin{tabular}{|c|c|c|c|c|}
\hline S. No. & $\begin{array}{c}\text { Clinical fea- } \\
\text { tures }\end{array}$ & Case 1 & Case 2 & Case 3 \\
\hline 1 & Age and sex & 21 year, $\mathrm{F}$ & 19 year, $\mathrm{F}$ & 25 year, $F$ \\
\hline 2 & Marital status & Unmarried & Unmarried & Unmarried \\
\hline 3 & $\begin{array}{l}\text { Socio-econom- } \\
\text { ic status }\end{array}$ & Low & Low & Low \\
\hline 4 & $\begin{array}{l}\text { Body mass in- } \\
\text { dex }\end{array}$ & 17.7 & 15.9 & 20.8 \\
\hline 5 & Splenectomy & No & No & No \\
\hline 6 & Haemoglobin & 9 & 10 & 9 \\
\hline 7 & Platelet count & $1,77,000$ & $3,50,000$ & $1,79,000$ \\
\hline 8 & $\begin{array}{l}\text { Prothrombin } \\
\text { time, aPTT }\end{array}$ & Normal & Normal & Normal \\
\hline 9 & $\begin{array}{l}\text { Serum ferritin } \\
(\mathrm{ng} / \mathrm{mL})\end{array}$ & 1824 & 2542 & 4325 \\
\hline 10 & HBV, HCV, HIV & Negative & Negative & Negative \\
\hline 11 & $\begin{array}{c}\text { Antinuclear } \\
\text { antibodies }\end{array}$ & Negative & Negative & Negative \\
\hline 12 & $\begin{array}{l}\text { Antistreptoly- } \\
\sin 0\end{array}$ & $<200$ units & $<200$ units & $<200$ units \\
\hline 13 & $\begin{array}{l}\text { C-reactive pro- } \\
\text { tein }\end{array}$ & Negative & Negative & Negative \\
\hline 14 & $\begin{array}{l}\text { Serum TSH, liv- } \\
\text { er and kidney } \\
\text { biochemistry } \\
\text { profile }\end{array}$ & Normal & Normal & Normal \\
\hline 15 & Chelating drug & Deferiprone & Deferiprone & Deferasirox \\
\hline
\end{tabular}

Case 2

Patient presented with acute onset pain right hip joint. Pain was incapacitating to the extent that patient was bedconfined. Objectively there were painful right hip joint movements with resultant restriction of movements but no local erythema, fever or other constitutional symptoms. Radiographic evidence of joint effusion was present. On probing, a history of gum bleeding was present for the last two months. Patient was administered vitamin C $500 \mathrm{mg}$ OD. By the fifth day of therapy, patient had remarkable improvement, with return of ambulation, disappearance of pain in hip joint and restoration of movements.
Case 3

Patient developed acute onset severe pain in right knee joint. No history of recent trauma or fever was available. Rheumatoid factor was negative. X-ray knee joint showed effusion and MRI revealed haemorrhage in suprapatellar and retropatellar bursa (fig 2) and significant inflammatory changes in the muscles around the joint. Deferasirox, a recently introduced iron-chelator was stopped but the patient did not benefit. Vitamin C was instituted and on the fourth day of therapy pain subsided and patient became ambulatory.

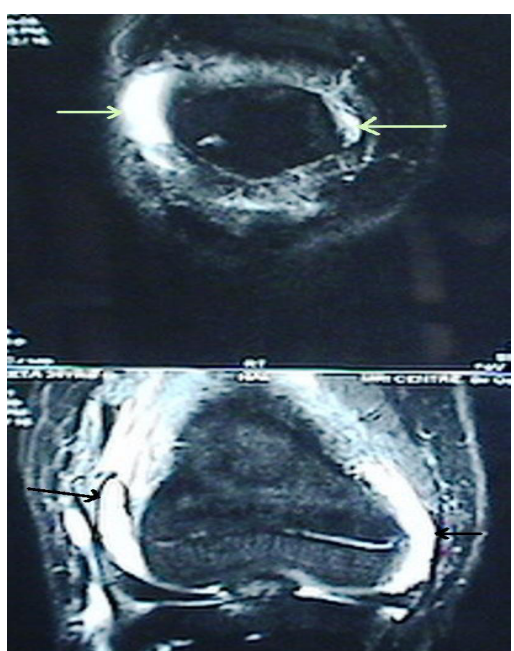

Figure 2. MRI of Right Knee Joint in Case 3. (Arrows indicate haemorrhagic effusion).

\section{DISCUSSION}

The three adult thalassemia cases receiving continuous "transfusion-chelation" therapy presented uniquely- one presented with non-thrombocytopenic non-palpable purpura, the second with effusion of right hip joint while the third had haemorrhagic effusion in the right knee joint. The first two cases had a history of gum bleed too. Gum bleeds, purpuric rash, serous/haemorrhagic joint effusions make for a clinical diagnosis of scurvy; and the response to therapy is dramatic. It is important to be aware that scurvy can occur in adult thalassemic patients and therefore, a high index of suspicion for diagnosis of scurvy should be kept. All the patients belonged to the low socio-economic strata of the society and in the present day rising inflation, affording fruits and vegetables (the primary sources of vitamin C); for this segment is very difficult. Incidentally, all three cases are females, and probably that may have to do with the malnutrition that the fairer sex is subjected to in the lower socio-economic segment, especially when the family is already burdened with a chronic illness like thalassemia in one of its family members.

The fact that these cases were suffering from thalassemia and receiving chelation therapy further complicates the matters. The first point that comes to the mind is "What is the relation of ascorbic acid to iron overload states 
arising out of multiple blood transfusions as in thalassemic patients". Way back in 1960s, it was demonstrated that cases of transfusional siderosis had reduced levels of white cell ascorbic acid and that severe dietary iron overload (Bantu patients) contributes to development of scurvy. ${ }^{1}$ Further, $64 \%$ of unchelated thalassemia major patients, specially the older and more transfused patients, were found to have subnormal leucocyte ascorbate concentrations without clinical evidence of scurvy. ${ }^{2}$ In iron-overloaded thalassemics, iron is stored in the reticuloendothelial system in the ferric form as ferritin. Ascorbic acid is an antioxidant and gets depleted while converting ferric to ferrous form. This is the postulated reason why a subclinical vitamin C deficiency exists in iron-overloaded states. Interestingly, oral vitamin $\mathrm{C}$ has been reported to be effective in promoting desferrioxamine induced iron excretion, by resulting in release of iron from stores or converting ferric to ferrous iron. ${ }^{3}$ Therefore, there is no doubt that multiple transfusions and inadequate chelation predispose to a state of sub-clinical vitamin C deficiency and as the longevity of life in thalassemia increases, one must keep scurvy at the back of mind while dealing with adult thalassemics.

The other intriguing aspect brought about by these cases is whether arthropathy in thalassemics could be (i) a manifestation of scurvy, (ii) secondary to para-articular bone thinning as a consequence of marrow expansion seen in thalassemmia, (iii) secondary to iron-chelator drugs, (iv) a reaction to blood transfusion or (v) part of rheumatic or collagen vascular disorders. ${ }^{4}$ There was no temporal association of symptoms with blood transfusion, the connective tissue profile was negative and in the absence of associated specific rheumatological signs/ symptoms; the latter two possibilities can virtually be ruled out. A distinct possibility of drug-related arthropathy should always be considered, but it is characterised by joint effusion, subchondral bone irregularity, patellar beaks and a distinct MRI picture, which was not the case. ${ }^{5}$ Similarly, no evidence of marrow expansion/ para-articular bone thinning was evident radiologically. However, serous and haemorrhagic joint effusions have been described in scurvy. In fact, almost a century ago, scurvy was considered to bear a relation to rheumatic fever. ${ }^{6} \mathrm{~A}$ condition of latent scurvy served as the substrate and superimposed infection manifested as rheumatic fever; and a defect in collagen was thought to be the fundamental alteration common to both scurvy and rheumatic fever. Haemorrhagic and serous effusions and arthritis have been described in scurvy as well. ${ }^{7-9}$ Scurvy in transfusion-dependent adult thalassemics has not been reported from India although scurvy in a thalassemic boy was reported a decade back. ${ }^{10}$

These three cases highlight that even today nutritional disorders like scurvy exist and should always be at the back of the doctor's mind when dealing with multiply-transfused patients like thalassemia patients. A high index of suspicion is essential to arrive at a diagnosis, the treatment of which is rather simple.

\section{REFERENCES}

1. Wapnick AA, Lynch SR, Krawitz P, Seftel HC, Charlton RW, Bothwell TH. Effects of iron overload on ascorbic acid metabolism. BMJ. 1968; 3: 704-7.

2. Chapman RW, Hussain MA, Gorman A, Laulicht M, Politis D, Flynn DM, et al. Effect of ascorbic acid deficiency on serum ferritin concentration in patients with $\beta$-thalassemia major and iron overload. J Clin Pathol 1982; 35: 487-91.

3. Pippard MJ, Callender ST, Finch CA. Ferrioxamine excretion in ironloaded man. Blood. 1982; 60: 288-94.

4. Dorwart BB, Schumacher HR. Arthritis in beta thalassemia trait: clinical and pathological features. Ann Rheum Dis. 1981; 40: 185-9.

5. Kellenberger CJ, Schmugge M, Saurenmann T, Gennaro LD, Eber SW, Willi UV, et al. Radiographic and MRI features of Deferipronerelated arthropathy of the knees in patients with $\beta$-thalassemia. Am J Roentgenol. 2004; 183: 989-94.

6. Rinehart JF, Connor CL, Mettier SR. Further observations on pathologic similarities between experimental scurvy combined with infection, and rheumatic fever. J Exp Med. 1934; 59: 97-114.

7. Kumar V, Choudhury P. Scurvy-a forgotten disease with an unusual presentation. Trop Doct. 2009; 39: 190-2.

8. Vitale A, La Torre F, Martini G, Calcagno G, Fede C, Conti G, et al. Arthritis and gum bleeding in two children. I Paediatr Child Health 2009; 45: 158-60.

9. Pangan AL, Robinson D. Hemarthrosis as initial presentation of scurvy. J Rheumatol. 2001; 28: 1923-5.

10. Ray M, Marwaha RK, Sethuraman G, Trehan A. Scurvy in transfusion dependent beta-thalassemia. Indian Pediatr. 1999; 36: 504-506. 